\title{
HUBUNGAN DUKUNGAN SOSIAL SUAMI DENGAN TINGKAT KECEMASAN IBU PRE MENOPAUSE DI DUSUN WONOKERTO DESA WONOKERTO KECAMATAN KEDUNGGALAR NGAWI
}

\author{
Oleh : \\ Tunjung Sri Yulianti ${ }^{1}$, Endang Dwi Ningsih ${ }^{2}$, Ahmad Nur Kholik ${ }^{3}$
}

\begin{abstract}
The background of this research is that women will enter menopause usually will experience physical and psychological changes that will cause anxiety. With the social support from her husband will make her feelings become calm, and feel cared for so as to reduce the anxiety. The results of a preliminary survey data obtained 2 of 4 pre-menopausal women say feel anxious, feel a lot of diseases that can attack the body after their menopause, feeling old, wrinkled and no longer pretty scared of her husband so they could later turn to other women.

The purpose of this study was to determine the relationship of husband's social support to pre menopausal women's anxiety levels at Hamlet Village Wonokerto Wonokerto Kedunggalar Ngawi subdistrict.

The subject of this study are all pre-menopausal women in Hamlet Village Wonokerto Wonokerto District of Kedunggalar Ngawi totaling 20 people by using total sampling techniques.

Methods of data collection in this study conducted by interview and observation then analyzed with Chi Square with a significant level of $\mathrm{p}: 0.05$.

The results of this study are the husband's social support included in optimal category and pre menopausal women's anxiety levels included in the category of no anxiety. Analysis with Chi Square test with $p=0.05$, obtained 0,031 results (probability <0.05).

The conclusion of this study is that there is a significant relationship between husband's social support with pre menopausal women's anxiety levels at Hamlet Village Wonokerto Wonokerto Kedunggalar Ngawi subdistrict.
\end{abstract}

Keywords: Menopause, Anxiety, Social Support

\section{PENDAHULUAN}

Menopause adalah masa terjadinya penghentian menstruasi permanen setelah hilangnya aktivitas ovarium. Tahun-tahun sebelum menopause yang meliputi perubahan dari siklussiklus ovulatorik normal ke penghentian mens dikenal sebagai tahun-tahun transisi menopause, ditandai oleh ketidakteraturan siklussiklus menstruasi.

Pada wanita rata-rata percepatan penghabisan folikel dan penurunan fertilisasi dimulai pada 37-38 tahun, dan menopause mengikuti kira-kira 13 tahun kemudian. Namun, pada penelitian-penelitian epidemiologik sekitar $10 \%$ wanita dari populasi umum mengalami menopause pada usia 45 tahun, kemungkinan karena mereka dilahirkan dengan kumpulan folikel ovarium yang lebih kecil dari normal yang secara fungsional habis pada usia lebih dini. (Hestiantoro, dkk., 2012)

Menurut survei Rumah Tangga (1986), makin banyak wanita Indonesia yang dapat melampaui 
usia menopause. Hapsoro menyatakan bahwa andaikata pada tahun 2000 nanti Indonesia sudah menjadi negara maju, 25\% dari penduduknya atau 27,5 juta wanita Indonesia akan mencapai usia menopause. Pada tahun tersebut usia harapan hidup penduduk Indonesia dapat mencapai 65 tahun. Keadaan ini mempunyai dampak pada dunia kesehatan, dikarenakan sekitar 27,5 juta wanita Indonesia harus hidup 15 tahun atau lebih tanpa fungsi ovarium atau hidup dengan defisiensi hormon estrogen. Sedangkan perubahan psikologis biasanya adalah rasa cemas, yang dapat berlangsung selama 5-10 tahun. (Darmojo dan Martono, 2006) Wanita yang akan menghadapi menopause biasanya akan merasa sangat cemas, meraka beranggapan bahwa menopause berarti akhir dari era reproduksi, yang berarti berhentinya nafsu seksual dan fisik serta mengakibatkan penuaan. (Darmojo dan Martono, 2006) Biasanya dalam menanggulangi kecemasan individu dapat mengunakan atau mengambil sumber koping dari lingkungan baik dari sosial, intrapersonal dan interpersonal. (Suliswati, dkk., 2005)

Samson (1983) sebagaimana dikutip oleh Azizah (2011) berpendapat bahwa dukungan sosial itu selalu mencakup dua hal yaitu mengharapkan bantuan dan kerabat dekat, kerabat jauh, dan kemudian yang terakhir adalah panti wreda. Dalam hal ini orang yang merasa memperoleh dukungan sosial, secara emosional merasa lega karena diperhatikan, mendapat saran atau kesan yang menyenangkan pada dirinya.

Hasil survey dan wawancara pendahuluan pada beberapa ibu pre menopause di Dusun Wonokerto Desa Wonokerto Kecamatan Kedunggalar menjelaskan bahwa 2 dari 4 ibu pre menopause mengatakan menopause tidak perlu dicemaskan karena menopause merupakan proses alami yang akan dilewati setiap wanita yang sudah menginjak umur 40-50 tahun. Sedangkan 2 orang lainnya mengatakan mereka merasa cemas, merasa banyak penyakit yang bisa menyerang tubuhnya setelah mereka menopause, merasa dirinya sudah tua, keriput dan tidak cantik lagi sehingga mereka takut suaminya nanti bisa berpaling ke wanita lain.

Berdasarkan kondisi di atas maka peneliti tertarik melakukan penelitian tentang Hubungan Dukungan Sosial Suami dengan Tingkat Kecemasan Ibu Pre Menopause di Desa Wonokerto Kecamatan Kedunggalar Ngawi. Tujuan Penelitian ini adalah untuk mengetahui hubungan dukungan sosial suami dengan tingkat kecemasan ibu pre menopause di Dusun Wonokerto Desa Wonokerto Kecamatan Kedunggalar Ngawi.

\section{METODE PENELITIAN}

Penelitian ini merupakan penelitian analitik, dengan desain penelitian korelasi dan pendekatan cross sectional. Penelitian korelasi bertujuan untuk mengungkapkan hubungan korelatif antar variabel. Sedangkan desain cross sectional merupakan rancangan penelitian yang pengukuran atau pengamatannya dilakukan secara simultan pada suatu saat (sekali waktu). (Hidayat, 2008)

Populasi dalam penelitian ini adalah ibu pre menopause yang berusia 4050 tahun di Dusun Wonokerto Desa Wonokerto Kecamatan Kedunggalar Ngawi sejumlah 20 orang. Sampel penelitian adalah semua ibu pre menopause di Dusun Wonokerto Desa Wonokerto Kecamatan 
Kedunggalar Ngawi yang berjumlah 20 orang dengan teknik sampling jenuh. Peneliti menggunakan alat ukur kuesioner untuk mengambil data masing-masing variabel. Metode pengumpulan data dengan cara observasi langsung kepada subjek.

\section{HASIL PENELITIAN}

Hasil penelitian yang diperoleh terkait dengan variabel Dukungan sosial suami dari 20 responden adalah sebagai berikut :

Tabel 1. Distribusi Frekuensi Dukungan Sosial Suami

\begin{tabular}{|c|c|c|}
\hline $\begin{array}{c}\text { Dukungan } \\
\text { Sosial } \\
\text { Suami }\end{array}$ & $\mathrm{F}$ & $\%$ \\
\hline $\begin{array}{c}\text { Kurang } \\
\text { Optimal }\end{array}$ & 3 & $15 \%$ \\
\hline Optimal & 17 & $85 \%$ \\
\hline Jumlah & 20 & $100 \%$ \\
\hline
\end{tabular}

Dari tabel di atas didapatkan data ada 17 responden (85\%) memiliki dukungan sosial suami yang optimal dan 3 responden (15\%) memiliki dukungan sosial suami kurang optimal. Adapun rata-rata dukungan sosial yang diberikan adalah optimal sesuai dengan tabel di bawah ini :

Tabel 2. Hasil Analisa Univariat Dukungan Sosial Suami

\begin{tabular}{|c|c|}
\hline $\begin{array}{c}\text { Analisa } \\
\text { Univariat }\end{array}$ & Hasil \\
\hline Mean & 14,75 \\
\hline Median & 16,00 \\
\hline Modus & 16 \\
\hline Std. Deviasi & 3,905 \\
\hline Range & 13 \\
\hline
\end{tabular}

Hasil penelitian yang diperoleh terkait dengan variabel Tingkat kecemasan ibu pre menopause adalah sebagai berikut :
Tabel 3. Distribusi Frekuensi Tingkat Kecemasan

\begin{tabular}{|c|c|c|}
\hline $\begin{array}{c}\text { Tingkat } \\
\text { Kecemasan }\end{array}$ & $\mathrm{F}$ & $\%$ \\
\hline $\begin{array}{c}\text { Tidak ada } \\
\text { kecemasan }\end{array}$ & 7 & $35 \%$ \\
\hline $\begin{array}{c}\text { Kecemasan } \\
\text { ringan }\end{array}$ & 6 & $30 \%$ \\
\hline $\begin{array}{c}\text { Kecemasan } \\
\text { sedang }\end{array}$ & 4 & $20 \%$ \\
\hline $\begin{array}{c}\text { Kecemasan } \\
\text { berat }\end{array}$ & 3 & $15 \%$ \\
\hline $\begin{array}{c}\text { Kecemasan } \\
\text { berat sekali }\end{array}$ & 0 & $0 \%$ \\
\hline Jumlah & 20 & $100 \%$ \\
\hline
\end{tabular}

Dari tabel di atas didapatkan data ada 7 responden (35\%) tidak ada kecemasan dan 3 responden (15\%) memiliki kecemasan berat. Hasil rata-rata untuk tingkat kecemasan adalah :

Tabel 4. Hasil Analisa Univariat Tingkat Kecemasan Ibu Pre Menopause

\begin{tabular}{|c|c|}
\hline $\begin{array}{c}\text { Analisa } \\
\text { Univariat }\end{array}$ & Hasil \\
\hline Mean & 17,30 \\
\hline Median & 17,50 \\
\hline Modus & 18 \\
\hline Std. Deviasi & 9,554 \\
\hline
\end{tabular}


Tabel 5. Tabulasi Silang Dukungan

Sosial Suami dengan Tingkat

Kecemasan Ibu Pre Menopause

\begin{tabular}{|c|c|c|c|c|c|c|}
\hline \multirow[b]{2}{*}{$\begin{array}{c}\text { Dukung } \\
\text { an } \\
\text { Sosial } \\
\text { Suami }\end{array}$} & \multicolumn{6}{|c|}{ Tingkat Kecemasan } \\
\hline & $\begin{array}{l}\text { T } \\
\mathrm{i} \\
\mathrm{d} \\
\mathrm{a} \\
\mathrm{k} \\
\mathrm{a} \\
\mathrm{d} \\
\mathrm{a}\end{array}$ & $\begin{array}{l}\mathrm{R} \\
\mathrm{i} \\
\mathrm{n} \\
\mathrm{g} \\
\mathrm{a} \\
\mathrm{n}\end{array}$ & $\begin{array}{l}S \\
\text { e } \\
d \\
a \\
n \\
g\end{array}$ & $\begin{array}{l}B \\
\text { e } \\
r \\
a \\
t\end{array}$ & $\begin{array}{l}\mathrm{r} \\
\mathrm{a} \\
\mathrm{t} \\
\mathrm{s} \\
\mathrm{e} \\
\mathrm{k} \\
\mathrm{a} \\
\mathrm{l} \\
\mathrm{i}\end{array}$ & $\begin{array}{l}\mathrm{J} \\
\mathrm{u} \\
\mathrm{m} \\
\mathrm{L} \\
\mathrm{a} \\
\mathrm{h}\end{array}$ \\
\hline $\begin{array}{l}\text { Kurang } \\
\text { Optimal }\end{array}$ & 0 & 0 & 1 & 2 & 0 & 3 \\
\hline Optimal & 7 & 6 & 3 & 1 & 0 & 17 \\
\hline Jumlah & 7 & 6 & 4 & 3 & 0 & 20 \\
\hline
\end{tabular}

Dari tabel di atas, peneliti menemukan bahwa : Responden yang dukungan sosial suaminya kurang optimal dengan tingkat kecemasan sedang sebanyak 1 responden. Responden yang dukungan sosial suaminya kurang optimal dengan tingkat kecemasan berat sebanyak 2 responden. Dukungan sosial suaminya optimal dan tidak ada kecemasan sebanyak 7 responden. Dukungan sosial suaminya optimal tetapi mengalami kecemasan ringan sebanyak 6 responden. Dukungan sosial suaminya optimal tetapi mengalami kecemasan sedang sebanyak 3 responden. Dukungan sosial suaminya optimal tetapi mengalami kecemasan berat sebanyak 1 responden.

Dari tabel di atas kemudian dilakukan perhitungan dengan Pearson Chi Square diperoleh hasil yaitu $p=0,031$ (probabilitas $<0,05$ ) sehingga $\mathrm{Ha}$ diterima, yang berarti ada hubungan yang signifikan antara dukungan sosial suami dengan tingkat kecemasan ibu pre menopause di Dusun Wonokerto
Desa Wonokerto Kecematan Kedunggalar. Besarnya hubungan 0,555 atau $55.5 \%$ dilihat dari nilai Contingency Coefficient.

\section{PEMBAHASAN}

Berdasarkan analisis univariat diperoleh data rata - rata dukungan sosial suami adalah optimal. Menurut Azizah (2011), dukungan sosial suami ini bisa berbentuk dukungan instrumental yaitu berupa penyediaan materi, dukungan informasional berupa pemberian informasi, dukungan emosional berupa pemberian perasaan nyaman maupun dicintai dan dukungan pada harga diri berupa penghargaan positif pada individu.

Dalam hal ini responden merasa memperoleh dukungan sosial, secara emosional merasa lega karena diperhatikan oleh suaminya, mendapat saran atau kesan yang menyenangkan pada dirinya. Dengan adanya dukungan sosial dari suami responden memperoleh ketentraman hidup. Sehingga tidak akan timbul rasa cemburu, kurangnya romantisme dan rasa kurang dihargai.

Rata-rata tingkat kecemasan ibu pre menopause adalah ringan. Menurut Hestiantoro, dkk (2012) menopause adalah masa terjadinya penghentian menstruasi permanen setelah hilangnya aktivitas ovarium. Perubahan psikologis yang terjadi adalah rasa cemas, yang dapat berlangsung selama 5-10 tahun. Wanita yang akan menghadapi menopause biasanya akan merasa sangat cemas, mereka beranggapan bahwa menopause berarti akhir dari era reproduksi, yang berarti berhentinya nafsu seksual dan fisik serta mengakibatkan penuaan. (Darmojo dan Martono, 2006)

Pada responden penelitian sebagian besar merasa kondisi yang akan 
mereka alami pada saat menopause merupakan situasi yang normal dialami oleh wanita sehingga tidak terlalu membuat responden khawatir. Menurut Suliswati, dkk (2005) kecemasan terjadi sebagai akibat dari ancaman terhadap harga diri atau identitas diri yang sangat mendasar bagi keberadaan individu. Hal yang bisa menimbulkan kecemasan biasanya bersumber dari ancaman integritas biologi seperti kebutuhan dasar, makan, minum, seks, dan ancaman terhadap keselamatan diri seperti tidak memperoleh pengakuan dari orang lain.

Berdasarkan analisa bivariat hubungan dukungan sosial suami dengan tingkat kecemasan ibu pre menopause didapatkan hasil bahwa ada hubungan antara dukungan sosial suami dengan tingkat kecemasan ibu pre menopause di Dusun Wonokerto Desa Wonokerto Kecematan Kedunggalar Ngawi. Hal ini ditunjukkan dengan nilai Contingency Coefficient sebesar 0,555 atau $55,5 \%$ dan nilai Pearson Chi Square sebesar 0,031 (probabilitas < 0,05) sehingga $\mathrm{Ha}$ diterima.

Walaupun rata-rata dukungan sosial suami optimal dan tingkat kecemasan ibu pre menopause adalah ringan tetapi masih ditemukan 3 responden (15\%) memiliki dukungan sosial suami yang kurang optimal dan mengalami kecemasan. Hal tersebut sesuai dengan paparan dari Darmojo dan Martono (2006) bahwa wanita yang menghadapi menopause biasanya mereka beranggapan bahwa menopause berarti akhir dari era reproduksi, yang berarti berhentinya nafsu seksual dan fisik serta mengakibatkan penuaan, menurut Suliswati, dkk. (2013) kecemasan tersebut dapat diatasi dengan mengambil sumber koping itu sendiri. Salah satu satu sumber koping itu adalah dukungan social. Dukungan dapat membuat perasaan ibu pre menopause lebih dihargai dan diperhatikan.

Dari data tabulasi silang diperoleh 7 responden $(35 \%)$ memiliki dukungan sosial suami yang optimal dan tidak mengalami kecemasan. Menurut Azizah (2011) dukungan yang diberikan dari suami dapat meningkatkan kepercayaan diri para istri sehingga bisa menjalani masa menopausenya dengan baik. Seseorang yang mendapat dukungan keluarga khususnya orang terdekat seperti suami dan anak anaknya akan merasa lega karena diperhatikan, merasa tenang dalam menghadapi masa - masa perubahan masa menopause.

Selain hasil tabulasi diatas, pada responden yang diteliti diperoleh 10 responden $(50 \%)$ memiliki dukungan sosial suami yang optimal tetapi memiliki kecemasan mulai dari tingkat ringan sampai berat. Hal ini dimungkinkan terjadi karena sumber koping yang lain tidak optimal. Menurut Suliswati, dkk. (2005) Sumber koping diantaranya adalah aset ekonomi, kemampuan memecahkan masalah, dan dukungan sosial budaya yang diyakini. Kemampuan individu dalam menanggulangi kecemasan secara konstruksi merupakan faktor utama yang membuat klien berperilaku patologis atau tidak. Bila individu sedang mengalami kecemasan dia akan mencoba menetralisasi, mengingkari atau meniadakan kecemasan dengan mengembangkan pola koping.

Pada 10 responden di atas masih mengalami kecemasan dari tingkat ringan sampai berat walaupun mendapatkan dukungan sosial yang optimal dari suami. Berdasarkan analisa peneliti hal ini mungkin disebabkan karena kemampuan 
individu dalam memecahkan masalah kurang baik sehingga timbul kecemasan. Tetapi hal ini masih memerlukan penelitian lebih lanjut.

\section{KESIMPULAN}

1. Dukungan sosial suami pada ibu pre menopause di Dusun Wonokerto Desa Wonokerto Kecamatan Kedunggalar Ngawi mayoritas termasuk dalam kategori optimal yaitu $85 \%$.

2. Tingkat kecemasan ibu pre menopause di Dusun Wonokerto Desa Wonokerto Kecamatan Kedunggalar Ngawi mayoritas termasuk dalam kategori tidak ada kecemasan yaitu $35 \%$.

3. Ada hubungan antara dukungan sosial suami dengan tingkat kecemasan ibu pre menopause di Dusun Wonokerto Desa Wonokerto Kecematan Kedunggalar Ngawi.

\section{SARAN}

1. Bagi lbu Pre Menopause Agar dapat menjaga kondisi fisik dan psikis tetap sehat supaya dapat mengantisipasi kecemasan dalam menghadapi menopause.

2. Bagi Suami

Agar mampu memberikan dukungan sosial yang tinggi dan meningkatkan pengetahuan mengenai menopause.

3. Bagi Puskesmas Setempat Agar dapat memberikan penyuluhan tentang bagaimana cara mengatasi kecemasan pada ibu pre menopause kepada ibu ibu yang akan mengalami menopause melalui kegiatan posyandu atau kegiatan lain yang memungkinkan.

\section{DAFTAR PUSTAKA}

Astarto, Winarto Nanang., dkk. Kupas Tuntas Kelainan Haid. Jakarta: CV Sagung Seto, 2011.

Azizah, Lilik Ma'rifatul. Keperawatan Lanjut Usia. Edisi Ke-1. Cetakan Ke-1. Yogyakarta: Graha IImu, 2011.

Darmojo, R. Boedhi dan H. Hadi Martono. Buku Ajar Geriatri (IImu Kesehatan Usia Lanjut). Edisi Ke-3. Cetakan Ke-2. Jakarta: FKUI, 2006.

Fox-Spencer, Rebecca dan Pam Brown. Simple Guide Menopause. Alih bahasa : Juwalita Surabsari dan Anna Koeswanti. Jakarta: Erlangga, 2007.

Hawari, Dadang. Manajemen STRES CEMAS dan DEPRESI. Edisi Ke-2. Cetakan Ke-3. Jakarta: FKUI, 2011.

Hestiantoro, Andon., dkk. Best Practices on IMPERIAL. Jakarta: CV Sagung Seto, 2012.

Hidayat, A. Aziz Alimul. Riset Keperawatan dan Teknik Penulisan IImiah. Edisi Ke-2. Cetakan Ke-3. Jakarta: Salemba Medika, 2008.

Metode Penelitian
Keperawatan dan Teknik
Analisis Data. Jakarta:
Salemba Medika, 2009.

Janiwarty, Bethsaida dan Herri Zan Pieter. Pendidikan Psikologi Untuk Bidan - Suatu Teori Dan Terapannya. Yogyakarta: Rapha Publishing, 2013. 
• KOsnเn“• JIK. Vol. 2 No. 1 Maret 2014

Kusmiran, Eny. Kesehatan Reproduksi Remaja dan Wanita. Cetakan Ke-2. Jakarta: Salemba Medika, 2012.

Lukluk, A Zuyina dan Siti Bandiyah. Psikologi Kesehatan. Yogyakarta : Nuha Medika, 2011.

Nugroho, Wahyudi. Keperawatan Gerontik \& Geriatrik. Edisi Ke3. Jakarta: EGC, 2008

Riwidikdo, Handoko. Statistik Untuk Penelitian Kesehatan dengan Aplikasi Program $R$ dan SPSS. Yogyakarta: Pustaka Rihama, 2009.
Suliswati, dkk. Konsep Dasar Keperawatan Kesehatan Jiwa. Jakarta: EGC, 2005.

Suyanto. Metode dan Aplikasi Penelitian Keperawatan. Yogyakarta: Nuha Medika, 2011.

Videbeck, Sheila L. Buku Ajar Keperawatan Jiwa. Alih bahasa : Renata Komalasari dan Alfrina Hany. Jakarta: EGC, 2008.

1 Dosen AKPER Panti Kosala Surakarta

2 Dosen AKPER Panti Kosala Surakarta

3 Mahasiswa AKPER Panti Kosala 